\title{
Diffusion in Cubic Sulphates
}

\author{
III. Divalent Cations in Pure Lithium Sulphate \\ Arnold Kvist, Ante Bengtzelius, and Ulf Trolle \\ Department of Physics, Chalmers University of Technology, Göteborg \\ (Z. Naturforsch. 23 a, 2042-2044 [1968] ; received 30 August 1968)
}

\begin{abstract}
The diffusion coefficients of the divalent ions $\mathrm{Mg}, \mathrm{Zn}, \mathrm{Ca}, \mathrm{Cd}$ and $\mathrm{Pb}$ have been measured between 600 and $800{ }^{\circ} \mathrm{C}$. The results can be described by an Arrhenius equation, where the preexponential factors decreases when the radius of the diffusing ion increases. By comparing results for univalent and divalent ions we have found that the formation energy is constant and that the migration energy decreases when the cation radius increases.
\end{abstract}

We reported recently on diffusion of univalent cations in cubic lithium sulphate ${ }^{1}$. Since we wanted to obtain more complete information about the transport mechanism in this salt, we have now studied diffusion of the divalent ions $\mathrm{Mg}, \mathrm{Zn}, \mathrm{Ca}, \mathrm{Cd}$ and $\mathrm{Pb}$ and also tried to investigate $\mathrm{Mn}, \mathrm{Ba}$ and $\mathrm{Be}$ diffusion.

The experimental technique has been described previously ${ }^{1}$. The results for $\mathrm{Ba}^{++}$and $\mathrm{Mn}^{++}$are only of qualitative nature due to difficulties with the chemical analysis, while for $\mathrm{Be}^{++}$we only found that the diffusion coefficient is very small.

The results are given in Table 1 and Fig. 1 . The diffusion coefficients are for all ions much greater than in "ordinary" solids. For instance for lithium sulphate at room temperature the diffusion coefficient is only about $0.5 \cdot 10^{-11} \mathrm{~cm}^{2} / \mathrm{s}$ (l. c. ${ }^{2}$ ).

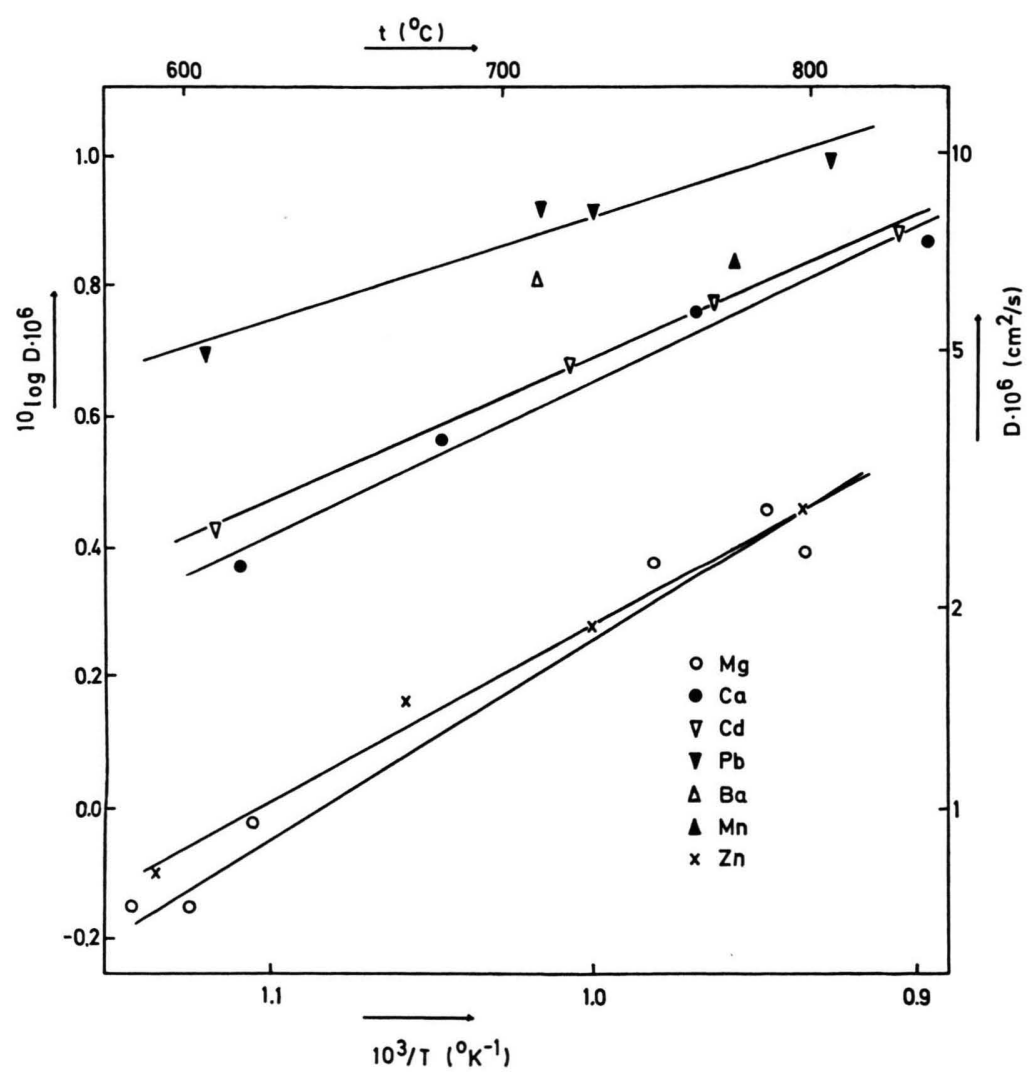

\begin{tabular}{|c|c|c|c|}
\hline Ion & $\stackrel{t}{t}$ & $\begin{array}{c}D \cdot 10^{5} \\
\mathrm{~cm}^{2} / \mathrm{s}\end{array}$ & $\begin{array}{l}\text { time } \\
\text { min }\end{array}$ \\
\hline \multirow[t]{4}{*}{$\mathrm{Cd}$} & 623 & 0.267 & 1305 \\
\hline & 720 & 0.477 & 985 \\
\hline & 766 & 0.597 & 640 \\
\hline & 832 & 0,762 & 385 \\
\hline \multirow[t]{4}{*}{$\mathrm{Ca}$} & 629 & 0.236 & 972 \\
\hline & 682 & 0.366 & 395 \\
\hline & 760 & 0.575 & 985 \\
\hline & 843 & 0.738 & 1317 \\
\hline \multirow[t]{6}{*}{$\mathrm{Mg}$} & 603 & 0.0706 & 2643 \\
\hline & 617 & 0.0704 & 4120 \\
\hline & 632 & 0.0947 & 2388 \\
\hline & 746 & 0.237 & 3685 \\
\hline & 784 & 0.286 & 1400 \\
\hline & 798 & 0.248 & 1192 \\
\hline \multirow[t]{4}{*}{$\mathrm{Zn}$} & 607 & 0.0790 & 1260 \\
\hline & 672 & 0.145 & 2555 \\
\hline & 728 & 0.189 & 985 \\
\hline & 797 & 0.288 & 2553 \\
\hline \multirow[t]{4}{*}{$\mathrm{Pb}$} & 621 & 0.493 & 324 \\
\hline & 711 & 0.823 & 352 \\
\hline & 728 & 0.820 & 475 \\
\hline & 807 & 0.986 & 366 \\
\hline Mn & 773 & 0.688 & 347 \\
\hline $\mathrm{Ba}$ & 710 & 0.642 & 516 \\
\hline
\end{tabular}

Fig. 1. The diffusion coefficients of divalent cations in cubic lithium sulphate.

1 A. Krist and A.Bengtzelius, Z. Naturforsch.23 a,679[1968]. ${ }^{2}$ E. D. Kuznets and L. M. Yakimenko, Zh. Prikl. Khim. 40, 786 [1967]. 
$D$ increases for the divalent ions, but decreases for the univalent ions when the ionic radii increase (Fig. 2), but if $D$ is described by an Arrhenius equation, $D=D_{0} \exp (-Q / R \mathrm{~T})$, it is found that $D_{0}$ and $Q$ decrease, when the ionic radii increase both for the univalent ${ }^{1}$ and divalent cations (Table 2). $Q$ is, however, considerably greater for the divalent than for the univalent cations.

\begin{tabular}{lrcrrr}
\hline Ion & $\begin{array}{c}D_{0} \cdot 10^{5} \\
\mathrm{~cm}^{2} / \mathrm{s}\end{array}$ & $\begin{array}{c}s_{D} \cdot 10^{5} \\
\mathrm{~cm}^{2} / s\end{array}$ & $\begin{array}{c}Q \\
\mathrm{cal} / \mathrm{mole}\end{array}$ & $\begin{array}{c}s_{Q} \\
\mathrm{cal} / \mathrm{mole}\end{array}$ & $\begin{array}{c}s_{D} \cdot 10^{5} \\
\mathrm{~cm}^{2} / \mathrm{s}\end{array}$ \\
\hline $\mathrm{Cd}^{++}$ & 72.3 & 8.2 & 9938 & 291 & 0.014 \\
$\mathrm{Ca}^{++}$ & 98.0 & 3.5 & 10693 & 878 & 0.039 \\
$\mathrm{Mg}^{++}$ & 183.1 & 8.3 & 13709 & 1033 & 0.003 \\
$\mathrm{Zn}^{++}$ & 101.0 & 2.7 & 12437 & 712 & 0.007 \\
$\mathrm{~Pb}^{++}$ & 31.2 & 5.7 & 7277 & 1005 & 0.057 \\
\hline
\end{tabular}

Table 2. The interdiffusion coefficients described by the relation $D=D_{0} \exp (-Q / R T) . s$ is the standard deviation.

\section{Discussion}

\section{The Activation Energy}

$Q$ is decreasing both for the univalent and the divalent cations when the ionic radii increase, but $Q$ for the divalent ions $\left(Q^{++}\right)$is considerably greater than the $Q$ values for the univalent cations $\left(Q^{+}\right)$, if ions with approximately the same radii are considered.

For our further discusison of $Q$ we have made some assumptions about the sulphate lattice and the distribution of the cations in the lattice.

In the sulphate lattice there are three lattice positions available for two cations ${ }^{3}$. The two smallest of these, the tetrahedral positions, can only accomodate lithium ions and perhaps sodium ions, while the greater one has a free space of about $3.18 \AA$ according to $\varnothing_{\mathrm{YE}}{ }^{4}$. All the other studied cations must thus jump between the octahedral positions.

We have now assumed that the distribution of the cations is independent of the temperature and that the number of vacancies introduced by the addition of the divalent impurity cations can be neglected compared with the number of empty octahedral lattice positions.

$Q$ can be written as the sum of a migration energy $\left(Q_{\mathrm{j}}\right)$ and a formation energy $\left(Q_{\mathrm{f}}\right) \cdot Q_{\mathrm{f}}$ must here be considered as the energy to create a suitable empty octahedral position. $Q_{\mathrm{j}}$ is the energy which is needed for an ion to pass the potential barrier between two octahedral positions. $Q_{\mathrm{j}}$ for the univalent ion $\left(Q_{\mathrm{j}}{ }^{+}\right)$should then be half that of a divalent ion $\left(Q_{\mathrm{j}}^{++}\right)$, if ions with equal ionic radii are considered. On the other hand the formation energy should be independent both of the ionic radius and the valency.

We thus obtain

$$
Q^{+}=Q_{\mathrm{j}}^{+}+Q_{\mathrm{f}}^{+}, \quad Q^{++}=2 Q_{\mathrm{j}}^{+}+Q_{\mathrm{f}}^{+},
$$

which gives

$$
Q_{\mathrm{j}}^{+}=Q^{++}-Q^{+}, Q_{\mathrm{f}}^{+}=2 Q^{+}-Q^{++} .
$$

$Q_{\mathrm{j}}$ and $Q_{\mathrm{f}}$ are both positive quantities and thus $2 Q^{+}>Q^{++}>Q^{+}$. This agrees with our experimental results and we can now easily calculate $Q_{\mathrm{j}}$ and $Q_{\mathrm{f}}$ by comparing ions with approximately the same radii (Table 3 ).

\begin{tabular}{lccc}
\hline $\begin{array}{c}\text { Univalent } \\
\text { cation }\end{array}$ & $\begin{array}{c}\text { Divalent } \\
\text { cation }\end{array}$ & $\begin{array}{c}Q_{j} \\
\text { kcal/mole }\end{array}$ & $\begin{array}{c}Q_{f} \\
\text { kcal/mole }\end{array}$ \\
\hline $\mathrm{Li}$ & $\mathrm{Zn}, \mathrm{Mg}$ & 5.1 & 2.8 \\
$\mathrm{Na}$ & $\mathrm{Ca}, \mathrm{Cd}$ & 4.2 & 3.0 \\
$\mathrm{~K}, \mathrm{Tl}$ & $\mathrm{Pb}$ & 1.5 & 2.9 \\
\hline
\end{tabular}

Table 3. The migration energy and formation energy calculated from Eq. (1) and Eq. (2).

$Q_{j}$ decreases when the cation radius increases, while the formation energy is constant and independent of the diffusing ion. This is in agreement with the model given above.

\section{The Pre-Exponential Factor}

No systematical investigations of $D_{0}$ for ionic compounds have been found in the literature. For metals $D_{0}$ generally falls between 0.1 and 0.5 with a comparably low accuracy.

As a general expression for $D_{0}$ one obtains

$$
D_{0}=g a^{2} v \exp \left(\left(S_{\mathrm{f}}+S_{\mathrm{j}}\right) / R\right),
$$

where $g$ is a geometrical factor not far from unity, $a$ a lattice parameter, $v$ the vibration frequency of the considered ion and $S_{\mathrm{f}}$ and $S_{\mathrm{j}}$ the entropies of formation and migration.

If we have the same transport mechanism for the different ions, $g$ and $a$ are independent of the diffusing ion. $v$ should be proportional to the inverse root of the reduced mass, but this relation can not ex-

${ }^{4} \mathrm{H} . \varnothing_{\mathrm{YE}}$, Thesis, Trondheim 1963. 


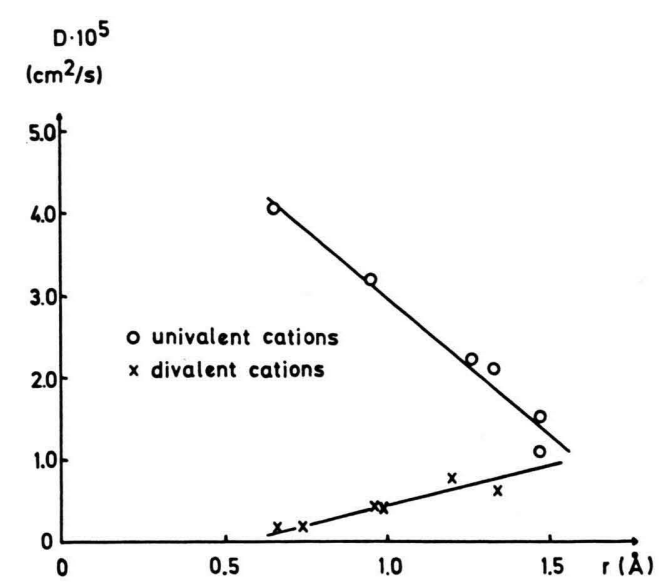

Fig. 2. The diffusion coefficients of univalent and divalent cations in cubic lithium sulphate as a function of the ionic radius at $700{ }^{\circ} \mathrm{C}$.

Fig. 3. The pre-exponential factor as a func- $\longrightarrow$ tion of the ionic radius.

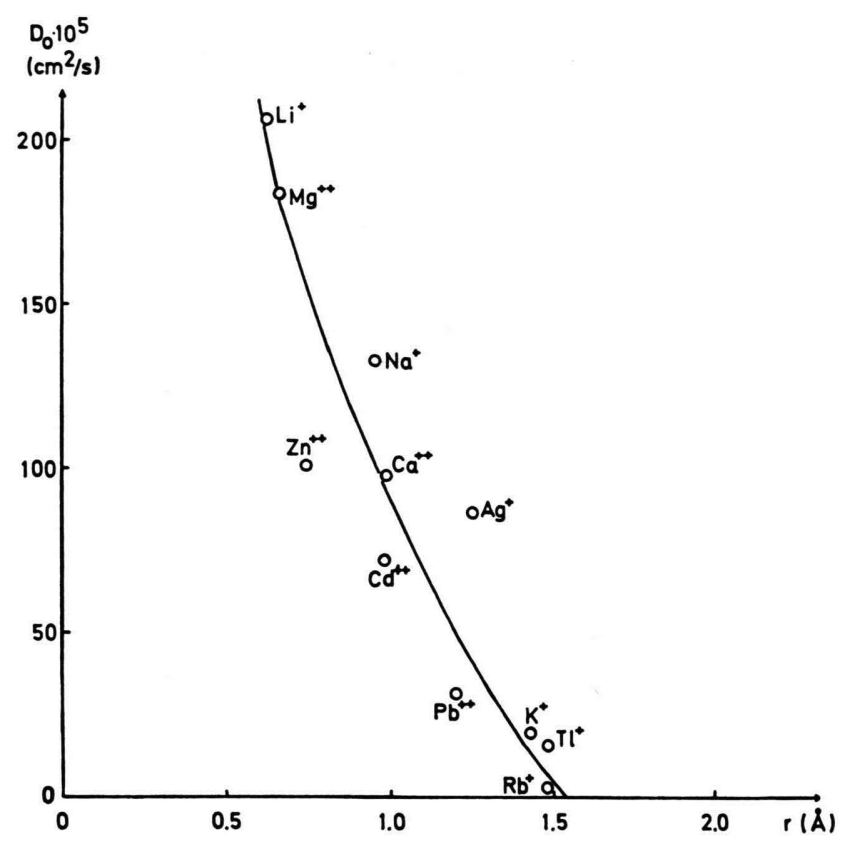

plain the behaviour of $D_{0}$ when the ionic radius increases, see Fig. 3 . The fast decrease in $D_{0}$ must thus be caused by a change in $S_{\mathrm{f}}$ or $S_{\mathrm{j}}$.

From the Eqs. (1) and (2) we found that $Q_{\mathrm{f}}$ is independent of the diffusing ion and there are thus reasons to believe that also the formation entropy is constant for the different ions. On the other hand the decrease in $Q_{\mathrm{j}}$ should correspond to a simultaneous change in $S_{\mathrm{j}}$.

It is seen in Fig. 3 that $D_{0}$ seems to go to zero (or to a very small value), when the ionic radius $r=1.56 \AA$, which should lead to very small diffu-

sion coefficients for a greater ion. For the sulphate ion for instance (ionic radius $2.4 \AA$ ) the diffusion coefficient should thus be neglectable compared with the cations. It should also be observed that the value $1.56 \AA$ is in good agreement with the radius of the octahedral position, $1.59 \AA$, found by $\varnothing_{\mathrm{YE}}{ }^{4}$ from X-ray investigations. The decrease in $Q_{\mathrm{j}}$ and $S_{\mathrm{j}}$ for the greater ions might thus be explained by a better fitting of these ions in the octahedral positions.

This work was financially supported by C. F. Lundströms Stiftelse. 